\title{
ASO Author Reflections: Adding up the Costs of Low-Value Breast Cancer Care
}

\author{
Brooke C. Bredbeck, MD ${ }^{1,2}$ (1) , and Lesly A. Dossett, MD, MPH ${ }^{1,2}$ \\ ${ }^{1}$ Department of Surgery, Michigan Medicine, Ann Arbor, MI; ${ }^{2}$ Center for Healthcare Outcomes and Policy, Michigan \\ Medicine, Ann Arbor, MI
}

\section{PAST}

More attention is being placed on value-based care, with a special focus on reducing the use of low-value interventions. ${ }^{1}$ Most women aged 70 and older with earlystage, hormone-receptor-positive breast cancer do not gain a survival benefit from either sentinel lymph node biopsy (SLNB) or adjuvant radiotherapy. National guidelines now support their omission. Despite these recommendations, SLNB and radiotherapy remain commonly used in this population. ${ }^{2}$ While existing literature is clear about the clinical implications of these interventions, the financial implications were not well understood.

\section{PRESENT}

This study demonstrates within a contemporary statewide payer database that utilization of SLNB and radiotherapy in older women with breast cancer remains high. ${ }^{3}$ Undergoing SLNB was associated with also undergoing adjuvant radiotherapy, suggesting SLNB may initiate a care cascade for further low-value care and higher spending. Spending for these treatments increased by up to $120 \%$ compared with surgery alone.

\section{FUTURE}

As there is greater scrutiny applied to rising costs of cancer care, clinicians and systems will be required to demonstrate value more explicitly. Greater knowledge and transparency regarding the spending associated with treatments will further empower all stakeholders to make valuebased treatment choices.

DISCLOSURES The authors declare no conflicts of interest.

\section{REFERENCES}

1. Wang T, Baskin AS, Dossett LA. Deimplementation of the choosing wisely recommendations for low-value breast cancer surgery: a systematic review. JAMA Surg. 2020. https://doi.org/10. 1001/jamasurg.2020.0322.

2. Wang T, Bredbeck BC, Sinco B, et al. Variations in persistent use of low-value breast cancer surgery. JAMA Surg. 2021. https://doi. org/10.1001/jamasurg.2020.6942.

3. Bredbeck BC, Baskin AS, Wang T, et al. Incremental spending associated with low-value treatments in older women with breast cancer. Ann Surg Oncol. 2021. https://doi.org/10.1245/s10434-02 1-10807-3.

Publisher's Note Springer Nature remains neutral with regard to jurisdictional claims in published maps and institutional affiliations.

(C) Society of Surgical Oncology 2021

First Received: 16 September 2021

Accepted: 16 September 2021;

Published Online: 29 September 2021

B. C. Bredbeck, MD

e-mail: Bbredbec@med.umich.edu 